\title{
HLA-B27 detection - comparison of genetic sequence-based method and flow cytometry assay
}

\author{
Urszula Skalska ${ }^{1}$, Anna Kozakiewicz ${ }^{1}$, Włodzimierz Maśliński ${ }^{1}$, Monika Jurkowska ${ }^{2}$ \\ ${ }^{1}$ Department of Pathophysiology and Immunology, Institute of Rheumatology, Warsaw, Poland \\ ${ }^{2}$ Department of Biochemistry and Molecular Biology, Institute of Rheumatology, Warsaw, Poland
}

\begin{abstract}
Objectives: The presence of human leukocyte antigen B27 (HLA-B27) is strongly associated with ankylosing spondylitis. HLA-B27 testing is routinely applied in the diagnosis of this disease. The aim of the present study was to compare two methods of HLA-B27 detection - a genetic sequence-based method and a flow cytometry assay.

Material and methods: Peripheral blood was obtained from 300 individuals with suspected spondyloarthropathy. Expression of HLA-B27 on the T cell surface was analysed by flow cytometry assay using GS145.2 monoclonal antibody specific for HLA-B27. DNA was isolated from the whole blood. Genes coding for HLA-B27, -B40 and -B47:01 were detected by polymerase chain reaction using the MW02/MW09 primer pair. Then, positive samples were sequenced in order to discriminate allelic variations of the HLA-B27 gene. Results of sequencing were analysed using Chromas LITE 2.1.1 software, BLAST software and the IMGT/HLA database. Ambiguous samples were additionally analysed by polymerase chain reaction using E91 and E136 primers amplifying a 135-bp fragment of the human HLA-B27 gene.

Results: Among 300 samples, 76 were HLA-B27-positive on the basis of flow cytometry analysis. Genetic sequence analysis confirmed positivity of 73 from among 76 samples. Two hundred twenty six samples were HLA-B27-negative, whereas the result of one sample analysis was ambiguous. Fifty-three samples were identified as allelic variation 27:05, 19 samples as allelic variation 27:02, and one sample as allelic variation 27:07.

Conclusions: This study shows that the genetic sequence-based method and the flow cytometry assay give consistent results in $99 \%$ of cases. The performed genetic analysis proves that the majority of HLA-B27-positive samples belong to the 27:05 allelic variation, which is strongly associated with high risk of ankylosing spondylitis.
\end{abstract}

Key words: HLA-B27, flow cytometry, DNA sequencing, allelic variants.

\section{Introduction and objective}

Human leukocyte antigen B27 (HLA-B27) is strongly associated with spondyloarthropathies, especially with ankylosing spondylitis (AS). HLA-B27 testing is routinely applied in the diagnosis of this disease. In the Caucasian race, HLA-B27 is present in $90 \%$ of patients suffering from AS, whereas among a healthy population it is present in $3 \%$ to $9 \%$ of individuals [1].
HLA-B27 has 105 currently known subtypes encoded by 132 allelic variants [2]. Not every allelic variant is disease-associated, and the strength of the association varies dependently on type of spondyloarthropathy and ethnicity of carriers. In the Caucasian race the 27:05 subtype is very strongly associated with AS [3]. Moreover, this subtype is the most widely distributed one in the Polish population [4]. Association with AS occurrence has

Address for correspondence:

Urszula Skalska, Department of Pathophysiology and Immunology, Institute of Rheumatology, Spartańska 1 ,

02-637 Warsaw, Poland, e-mail: urszula.skalska@ir.ids.pl

Submitted: 6.02.2015; Accepted: 2.04.2015 
been observed for 27:01-05, 27:07, 27:08, 27:10, 27:13-15, 27:19, 27:23, 27:24, 27:25 and 27:49 subtypes [2]. Some subtypes are not associated with increased risk of AS (27:09) or may play a protective role $(27: 06)[2,5]$.

The most widely used diagnostic method of HLA-B27 determination is the flow cytometry assay. In this assay, HLA-B27 on the T cell surface is detected using a specific monoclonal antibody. However, this method does not allow one to discriminate HLA-B27 allelic variants, which may be crucial for proper diagnosis. Analysis of HLA-B27 subtypes is possible only by means of genetic methods. The objective of the present study was to compare two methods of HLA-B27 detection: a flow cytometry assay and a genetic sequence-based method enabling distinction of allelic variants.

\section{Material and methods \\ Blood samples}

Peripheral blood was obtained from 300 patients with suspected spondyloarthropathy. All patients gave their written informed consent according to the Declaration of Helsinki. The study was approved by the Institute of Rheumatology Ethics Committee, Warsaw, Poland. Peripheral blood samples $(5 \mathrm{ml})$ were acquired in $\mathrm{K}_{3}$ EDTA. One part of every sample was analysed by flow cytometry, and another part was frozen at $-70^{\circ} \mathrm{C}$. After refreezing, DNA was isolated from $200 \mu$ lof blood (QIAamp DNA Blood Mini Kit, Qiagen, Germantown, MD, USA) and then used in polymerase chain reaction.

\section{Flow cytometry analysis}

The presence of HLA-B27 on peripheral blood T cells was detected by GS145.2 monoclonal antibody (HLA-B27 Kit, Becton Dickinson, San Jose, CA, USA). The whole procedure was performed according to the manufacturer's instructions. Blood samples were stained with anti-HLA-B27 antibody conjugated with fluorescein and with anti-CD3 antibody conjugated with phycoerythrin. Samples were incubated for 20 min in the dark, at room temperature, and then analysed using a FACSCalibur flow cytometer and HLA-B27 v3.1 software (Becton Dickinson, San Jose, CA, USA).

\section{Polymerase chain reaction}

Isolated DNA (75 ng) was amplified using $1.25 \mathrm{U}$ of Taq polymerase (Genoplast, Pruszków, Poland) and the MW02/MW09 primer pair [6]. These primers amplify a 666-bp fragment of human HLA-B27, -B40 and -B47:01 genes. The MW02 sequence is located in exon 2, whereas MW09 is located in exon 3 of target genes. A 268-bp fragment of human $\beta$-globin was also amplified as an amplification control. The final volume of reaction mix was $25 \mu \mathrm{l}, \mathrm{Mg}^{2+}$ concentration $-2 \mathrm{mM}$ and deoxynucleotide triphosphates concentration $-400 \mu \mathrm{M}$. Both primer pairs were used in $0.625 \mu \mathrm{M}$ concentration. Each sample was pre-incubated at $95^{\circ} \mathrm{C}$ for $3 \mathrm{~min}$ before cycling. The thermal profile of the reaction was: $35 \mathrm{~s}$ at $95^{\circ} \mathrm{C}, 45 \mathrm{~s}$ at $57^{\circ} \mathrm{C}$ and $45 \mathrm{~s}$ at $72^{\circ} \mathrm{C}$. After 30 cycles, 8 minutes of final elongation at $72^{\circ} \mathrm{C}$ completed the cycling program.

Samples that gave ambiguous results were additionally analysed using the E91/E136 primer pair (in a final concentration of $0.625 \mu \mathrm{M}$ ) amplifying a 135-bp fragment of the human HLA-B27 gene [7]. Both primers are localized in exon 3 of the HLA-B27 gene. The final reaction volume and concentration of reagents were similar as in previous reactions. The thermal profile was as follows: pre-incubation of samples at $95^{\circ} \mathrm{C}$ for $5 \mathrm{~min}, 30$ cycles composed of $45 \mathrm{~s}$ at $95^{\circ} \mathrm{C}, 60 \mathrm{~s}$ at $64^{\circ} \mathrm{C}, 60 \mathrm{~s}$ at $72^{\circ} \mathrm{C}$ and 7 minutes of final elongation at $72^{\circ} \mathrm{C}$. Primer sequences, localization and specificity are given in Table I.

Polymerase chain reaction products were size fractionated on $1.5 \%$ or $2 \%$ agarose gel (Genoplast, Pruszków, Poland) with addition of ethidium bromide (Sigma-Aldrich, St Louis, MO, USA) and photographed under UV transillumination (Vilber Lourmat, Marne La Valée, France).

Table I. Sequences, localization and specificity of the primers

\begin{tabular}{|c|c|c|c|}
\hline Primer & Localization & Sequence & Specificity \\
\hline MW02 forward & exon 2 & 5'-GCTACGTGGACGACACGCT-33 & \\
\hline MW09 reverse & exon 3 & 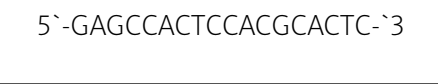 & $\begin{array}{c}\text { HLA-B27*, B40, } \\
\text { B47:01 }\end{array}$ \\
\hline MW16 forward & exon 2 & 5'-CGCCGCGAGTCCGAGAGA-`3 & HLA-B27 \\
\hline E91 forward & exon 3 & 5'-GGGTCTCACACCCTCCAGAAT-`3 & \\
\hline E136 reverse & exon 3 & $5^{\prime}-$ CGGCGGTCCAGGAGCT-`3 $^{-}$ & HLA-B27** \\
\hline$\beta$-globin forward & & 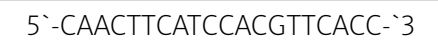 & \\
\hline$\beta$-globin reverse & & 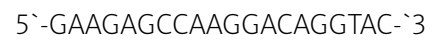 & $\beta$-globin \\
\hline
\end{tabular}

*excluding allelic variants: 27:15, 27:25, 27:28, 27:38, 27:47, 27:62, 27:63, 27:71, 27:76

**excluding allelic variants: 27:07, 27:14, 27:19, 27:21. 
Table II. Results of HLA-B27 detection analysis in 300 patients with suspected spondyloarthropathy

\begin{tabular}{|lcc|}
\hline HLA-B27 & Flow cytometry & PCR and sequencing \\
\hline Positive & 76 & 73 \\
$27: 05$ & & 53 \\
27:02 & & 19 \\
27:07 & 1 \\
\hline Negative & 224 & 226 \\
\hline Ambiguous & & 1 \\
\hline
\end{tabular}

All primer pairs used in this study were synthesized in the Laboratory of DNA Sequencing and Oligonucleotide Synthesis, Institute of Biochemistry and Biophysics PAN, Warsaw, Poland.

\section{Sequencing of polymerase chain reaction products}

Based on agarose gel analysis, samples positive for human HLA-B27, -B40 and -B47:01 genes were selected and sequenced (automated fluorescence-based sequencing) using the HLA-B27-specific MW16 primer [6]. Sequencing was performed in the Genomed Laboratory, Warsaw, Poland. The MW16 sequence is located in exon 2 of the HLA-B27 gene. Obtained sequences were about 600 bp long and covered part of exon 2, intron 2 and part of exon 3 (Table I). DNA concentration in sequenced samples was $40 \mathrm{ng} / \mathrm{ml}$, and MW16 primer concentra-
Table III. Samples giving incoherent results

\begin{tabular}{|llll|}
\hline Sample no. & $\begin{array}{c}\text { Flow } \\
\text { cytometry }\end{array}$ & $\begin{array}{c}\text { PCR MW02/ } \\
\text { MW09 and } \\
\text { sequencing }\end{array}$ & $\begin{array}{c}\text { PCR E91/ } \\
\text { E136 }\end{array}$ \\
\hline 56 & positive & negative & positive \\
\hline 162 & positive & negative & negative \\
\hline 355 & positive & negative & negative \\
\hline
\end{tabular}

tion was $5 \mu \mathrm{M}$. Obtained sequences were analysed using Chromas LITE 2.1.1 software (Technelysium Pty Ltd, South Brisbane, Australia), BLAST software (National Library of Medicine, Bethesda, MD, USA) and the IMGT/ HLA database (www.ebi.ac.uk/ipd/imgt/hla/).

\section{Results}

The results of flow cytometry analysis showed that among 300 samples, 76 were HLA-B27-positive (Table II). Genetic sequence analysis confirmed the positivity of 73 from among these 76 samples. 226 samples were negative, whereas one sample was impossible to interpret using the sequence-based method. The sequencing revealed that 53 samples were allelic variant 27:05, 19 samples were 27:02 and 1 sample was 27:07.

In samples 56, 162 and 355, HLA-B27 was detected by flow cytometry, but was impossible to detect on the basis of the genetic method (Figs. 1 and 2). Polymerase chain
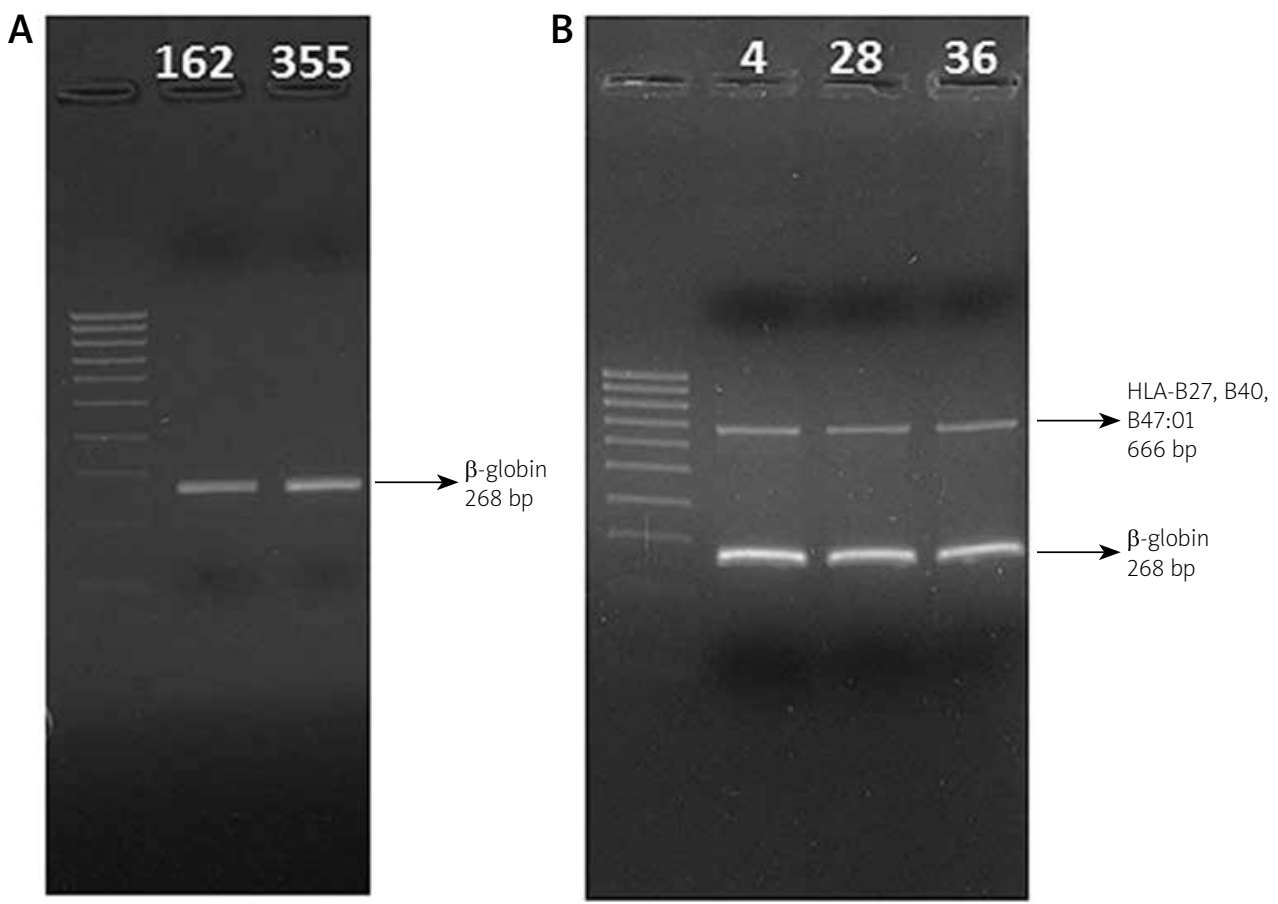

Fig. 1. Products of PCR amplifying HLA-B27, -B40, -B47:01 and $\beta$-globin genes. Agarose gel (1.5\%) electrophoresis. A - HLA-B27-negative samples no. 162 and 355. B - exemplary HLA-B27-positive samples no. 4, 28 and 36. 

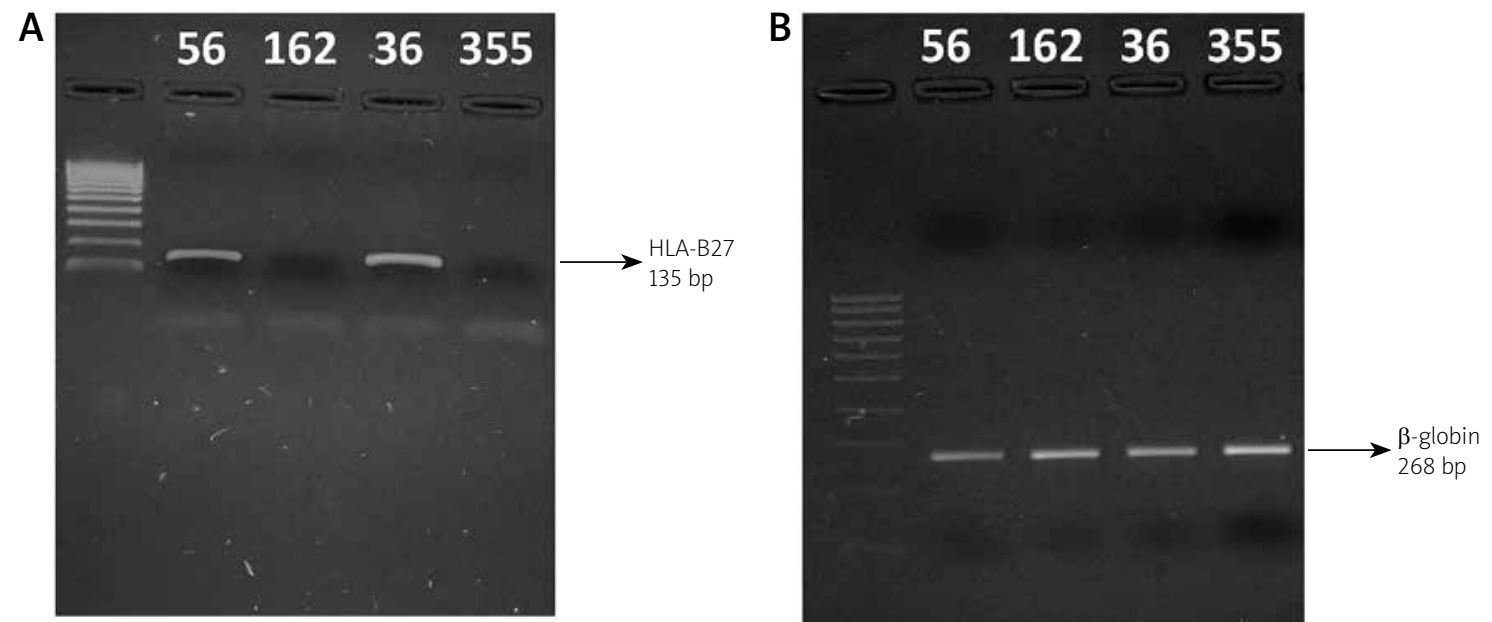

Fig. 2. PCR products generated using E91 and E136 primers. Agarose gel (2\%) electrophoresis; DNA isolated from samples no. 56, 162, 355 and from exemplary HLA-B27-positive sample no. 36. A - HLA-B27 gene amplification. $\mathrm{B}-\beta$-globin gene amplification. DNA ladder ranges from 100 to $1000 \mathrm{bp}$.

reaction using MW02 and MW09 primers generated a 666 -bp product in sample 56 , but sequencing excluded the HLA-B27 gene. This result was inconsistent with the GS145.2 antibody assay. Interestingly, PCR performed using E91 and E136 primers proved HLA-B27 gene presence in sample 56 (Fig. 2). In the case of samples 162 and 355, the PCR with both primer pairs did not generate any products, which indicates that the donors were HLA-B27/B40/ B47:01-negative (Figs. 1 and 2). $\beta$-globin gene detection in these samples excluded false negative results (Fig. 1A). Three incoherent results are summarized in Table III.

\section{Discussion and conclusions}

The flow cytometry assay and sequence-based method used in this study bring consistent results in $99 \%$ of cases. The flow cytometry assay can give false negative results due to the cross-reactivity of GS145.2 antibody with HLA-B07 [8], which may explain the incoherent results in the case of samples 162 and 355 (Figs. 1 and 2). Although MW02/MW09 and E91/E136 primer pairs used in this study do not anneal with every HLA-B27 allelic variant (Table I), the application of both pairs ensured potential detection of all subtypes.

Results obtained for sample 56 are difficult to interpret (Table III, Fig. 2). PCR using MW02/MW09 primers and sequencing suggest that the donor of this sample is the carrier of HLA-B40 or HLA-B47:01, but the flow cytometry analysis proved the presence of HLA-B27. The possible explanation of these contradictory results may be the fact that GS145.2 antibody also cross-reacts with HLA-B40 [8]. Nevertheless, PCR with E91/E136 primers indicates that the donor may be a carrier of the HLA-B27 gene. The E91/E136 primer sequences are located in exon 3, whereas the MW16 primer (used for sequencing) is located in exon 2 of the HLA-B27 gene. Thus, we can speculate that the donor might carry some mutations in exon 2 which precluded annealing of the MW16 primer, but did not affect recognition of the epitope by GS145.2 antibody. It is known that there are only a few specific amino acid residues crucial for GS145.2 antibody binding to HLA-B27 [9].

The performed genetic analysis proved that all positive samples belong to the three most popular HLA-B27 subtypes in the Polish population: 27:05, 27:02 and 27:07 [4]. As already mentioned, the risk of AS is not the same for every HLA-B27 carrier and is associated with particular allelic variants of HLA-B27. Cytometric analysis revealed that 76 patients were HLA-B27-positive, but as a result of the genetic analysis we were able to demonstrate that in the vast majority of positive patients $(n=53)$, the 27:05 allelic variant was present. Because this subtype strongly correlates with great risk of AS [3], we can conclude that the sequence-based method enables better and more reliable diagnosis of this disease.

This study was supported by the grant "Development of innovative test in the area of genetics based on the NGS technology" no. UDA-POIG.01.04.00-30-027/12-00 co-financed by the European Union under the European Regional Development Fund - Activity 1.4, Innovative Economy Operational Program.

The authors declare no conflict of interest.

\section{References}

1. Roelandse-Koop EA, Buisman B, van Hannen EJ, et al. Rapid HLA-B27 screening with real-time TaqMan PCR: a clinical vali- 
dation in the Dutch population. Clin Chem Lab Med 2011; 49: 1979-1985.

2. Khan MA. Polymorphism of HLA-B27: 105 subtypes currently known. Curr Rheumatol Rep 2013; 15: 362-367.

3. Khan M. HLA in spondyloarthropathies. In: The HLA Complex in Biology and Medicine. A resource Book. Mehra NK (ed.). Jaypee Brothers Medical Publishers Ltd., New Delhi, India 2010; 259-275.

4. Schmidt AH, Solloch UV, Pingel J, et al. High-resolution human leukocyte antigen allele and haplotype frequencies of the Polish population based on 20,653 stem cell donors. Hum Immunol 2011; 72: 558-565.

5. Kontny E. Nowe aspekty patogenezy spondyloartropatii zapalnych. Część I. Uwarunkowania genetyczne i rola cząsteczek HLA-B27. Reumatologia 2014; 52: 105-111.

6. Blasczyk R, Weber M, van Lessen A, et al. Discrimination of HLA-B27 alleles by group-specific amplification followed by solid-phase sequencing. Hum Immunol 1996; 45: 117-123.

7. Seipp MT, Erali M, Wies RL, Wittwer C. HLA-B27 typing: evaluation of an allele-specific PCR melting assay and two flow cytometric antigen assays. Cytometry B Clin Cytom 2005; 638: 10-15.

8. Levering $\mathrm{WH}$, Wind $\mathrm{H}$, Sintnicolaas $\mathrm{K}$, et al. Flow cytometric HLA-B27 screening: cross-reactivity patterns of commercially available anti-HLA-B27 monoclonal antibodies with other HLA-B antigens. Cytometry B Clin Cytom 2003; 54: 28-38.

9. Taurog JD, el-Zaatari FA. In vitro mutagenesis of HLA-B27. Substitution of an unpaired cysteine residue in the $\alpha_{1}$ domain causes loss of antibody-defined epitopes. J Clin Invest 1988; 82: 987-992. 